\title{
Microbial Contaminants in the Commercial Aviation Fuel Obtained from Benin City Airport, Nigeria
}

\author{
Onuorah Samuel $^{1, *}$, Obika Ifeanyi ${ }^{2}$, Orji Michael $^{1}$, Odibo Frederick ${ }^{1}$ \\ ${ }^{1}$ Department of Applied Microbiology and Brewing, Nnamdi Azikiwe University, Nigeria \\ ${ }^{2}$ Department of Zoology, Nnamdi Azikiwe University, Nigeria
}

Copyright (C) 2015 by authors, all rights reserved. Authors agree that this article remains permanently open access under the terms of the Creative Commons Attribution License 4.0 International License

\begin{abstract}
The primary function of aviation fuel is to provide propulsive energy to the aircraft. Microorganisms may contribute to aging instability in the fuel, induce corrosion of the storage tanks and pipeworks, form mats which can block filters and pipelines and increase wear in fuel pumps eventually leading to engine failure, therefore, in this study, the microbial contaminants in the commercial aviation fuel obtained from Benin City Airport, Nigeria were isolated, characterized, identified and their hydrocarbon-utilizing potentials determined using standard methods. The microbial contaminants were Micrococcus luteus, Serratia marcescens, Pseudomonas aeruginosa, Bacillus subtilis, Citrobacter freundii, Klebsiella aerogenes, Acinetobacter calcoaceticus, Fusarium oxysporum, Penicillium italicum, Rhizopus stolonifer, Aspergillus fumigatus and Candida tropicalis. Serratia marcescens had the highest percentage distribution $(16 \%)$ in the fuel. Serratia marcescens, Pseudomonas aeruginosa, Acinetobacter calcoaceticus, Rhizopus stolonifer and Aspergillus fumigatus were the best utilizers of the fuel among the organisms isolated. There was a drop in the initial $\mathrm{pH}$ of the mineral salts oil medium inoculated with the isolates indicating hydrocarbon utilization. The result of this work showed that the fuel examined was contaminated with bacteria and fungi, therefore the incorporation of effective biocides, frequent inspection and drainage of water from fuel tanks and pipeworks are recommended.
\end{abstract}

Keywords Contaminants, Commercial, Aviation Fuel, Benin City, Airport

\section{Introduction}

Aviation fuel is a specialized type of petroleum-based fuel used to power aircraft. It is the kerosene cut from the distillation of petroleum and is a mixture of thousands of hydrocarbons [1]. It consists primarily of long, single branched chains of carbon and hydrogen, or alkanes, ranging from $\mathrm{C}_{10-} \mathrm{C}_{20}$ in length [2]. While the major component of jet fuel is alkanes, there are typically small amounts of aromatic hydrocarbons, sulfur, nitrogen and traces of metals [2]. Hydrocarbon chain length and molecular weight or carbon numbers are restricted by the operational requirement of the product such as the freezing point or smoke point [3].

Aviation fuel systems are an ideal environment for the proliferation of micro-organisms, as all physiological requirements for their growth are normally present [4]. Microorganisms require free water, organic nutrients, inorganic nutrients and proper temperature and ${ }_{\mathrm{p}} \mathrm{H}$ for growth [5]. Some microorganisms require oxygen for growth while others grow in the absence of oxygen. Microbes may also be able to metabolize some fuel additives such as surfactants, as nutrient sources, though others may have inhibiting behaviours [6,7]

Microorganisms found in aviation fuels include bacteria, yeasts and moulds. Organisms of concern appear to be a part of the normal environmental population [8]. Although some microorganisms appear most commonly in fuel systems, they do not seem to be particularly specialized for the hydrocarbon environment and appear to have other occupation in the natural environment [8].

These microbes appear to be widely and abundantly distributed in nature where they may be of considerable importance in the carbon cycle and to various industries [8], for example, microbial oxidation of hydrocarbons may help to account for the rapid disappearance of petroleum which pollutes fields and waterways, for the deterioration of certain rubber products both natural and synthetic, for the spoilage of cooling oils, for the depreciation of oiled or asphalt-surfaced highways and for the biodegradation of petroleum or its products stored in the presence of water.

The problems associated with microbial contamination of aviations fuel include sludge formation, aluminum corrosion and deterioration of structural properties of aluminum alloys, injector fouling, degradation of fuel quality, decreased life of engine parts due to breakdown of hydrocarbon, interference with engine performance, corrosion of fuel storage tanks and distribution equipments, malfunction of fuel gauges, 
increased water content of fuel, increased sulphur content of fuel, clogged fuel lines, oxygen and hydrogen scavenging, sulphate reduction, biosurfactant production and biofilm formation, additive and fuel molecule metabolism, damage to organic coatings and failure of water separators [2].

Two of the most commonly recognized symptoms of microbial contamination of aviation fuel are microbially-induced corrosion and plugged fuel filters caused by biofilms. A major problem associated with microbial contamination is the formation of biofilms. Biofilms are constructed and organized accumulations of microbes in matrices of extracellular polymeric substances, proteins, nucleic acids and other components [9,11]. They are essential for the transfer of metabolic products and for allowing nutrients, including oxygen through the system $[10,11]$.

The formation of biofilms can be influenced by many different factors including the types of microbes present, flow conditions, nutrient availability and local environmental parameters [10]. These biofilms may be composed of single species or a consortium of species. The microbes that initially colonize the surface are believed to alter the surface properties and thus permit the attachment of pioneer species [9]. The microbes present in a biofilm alter the ${ }_{\mathrm{P}} \mathrm{H}$, oxygen availability and types and levels of ions of the metal-solution boundary and thus influence corrosion [6].

In view of these problems associated with the use of microbially-contaminated aviation fuels, it became necessary to isolate, characterize and identify, the microorganisms in the commercial aviation fuel obtained from Benin City Airport Nigeria, which was the objective of this study.

\section{Materials and Methods}

\subsection{Collection of Samples}

The aviation fuel samples were collected from ten different fuel storage containers obtained Benin City Airport, Nigeria in sterile glass bottles. They are thereafter taken to the microbiology laboratory of Nnamdi Azikiwe University Awka, Nigeria on ice packs for analysis.

\subsection{Isolation of Microorganisms}

The method used by Onuorah et al [12] was used. The samples were enriched in nutrient broth for twenty-four hours and serially-diluted with physiological saline. One milliliter aliquots of the serially-diluted samples $\left(10^{4}\right.$ and $10^{3}$ for bacteria and fungi respectively) were evenly spread on sterile nutrient agar (NA) contained in culture plates.

Some of the plates had Ketoconazole at a concentration of $0.05 \mathrm{mg} / \mathrm{ml}$ added to inhibit fungal growth while others had chloramphenicol at a concentration of $0.05 \mathrm{mg} / \mathrm{ml}$ to inhibit bacterial growth. The plates were shaken gently to ensure even mixing. The plates were thereafter covered, allowed to solidify and later incubated in an inverted position at $28^{\circ} \mathrm{C}$ for seven days for bacteria and ten days in the case of fungi, after which the isolates were randomly selected, subcultured on nutrient agar plates and later transferred onto NA slants where they were stored for characterization, identification and further use.

\subsection{Characterization and Identification of the Bacterial Isolates}

The bacterial isolates were characterized morphologically and biochemically. Gram staining, catalase, motility, spore, methyl red, voges proskaeur, oxidase and sugar fermentation tests were performed. Molecular identification was also carried out. The isolates were identified according to the scheme of Holt [13].

\subsection{Characterization and Identification of the Fungal Isolates}

The fungi were characterized and identified on the basis of their colony morphology and microscopic features. The slide culture technique as well as microscopic examination was used to characterize and identify the molds while the yeasts were characterized and identified using the Germ tube, Motility, Gram stain, Sugar assimilation and Chlamydospores formation tests. A mycological atlas was used to confirm the identity of each fungus.

\subsubsection{Slide Culture Technique}

The method of Onuorah et al [14] was used. A sterile inoculating needle was used to inoculate a portion of the fungus on a slide containing potato dextrose agar. The slide was thereafter incubated at room temperature for twenty-four hours and viewed under the microscope.

\subsubsection{Microscopic Examination}

The microscopic examination was carried out using lactophenol cotton blue solution. A drop of $95 \%$ ethanol was placed on a microscopic slide. A fragment of the test fungus was gently teased into the ethanol. The slide was left for the ethanol to evaporate before a drop of lactophenol cotton blue solution was added. The slide was thereafter covered with a coverslip, avoiding bubbles. The stain was allowed to penetrate and the excess stain removed by blotting with Whatman No. 1 filter paper. The slide was thereafter viewed under the microscope.

\subsubsection{Germ Tube Test}

The procedure of Menza et al [15] was used. The test yeast was introduced into human serum and incubated at $37^{\circ} \mathrm{C}$ for three hours. A drop of the mixture was thereafter introduced on a microscope slide and covered with a coverslip and viewed under the microscope for the presence of germ tube.

\subsubsection{Motility Test}


Vaseline was spread with a sterile toothpick on the corners of a clean coverslip. A drop of the yeast suspension was aseptically introduced on the centre of the coverslip. The depression slide was lowered onto the coverslip so that the drop protruded into the centre of the concavity of the slide. The hanging drop slide was turned over and placed under the microscope so that the drop was on the right hole. The drop was then viewed under the microscope.

\subsubsection{Gram Staining}

A test yeast was smeared on a slide and stained using the gram staining procedure. The slide was thereafter viewed under the microscope.

\subsubsection{Sugar Assimilation Test}

The method employed by Onuorah et al [14] was used. Carbohydrate-impregnated filter paper discs were placed on sterile carbohydrate-free yeast nitrogen base agar contained in petridishes and incubated at $30^{\circ} \mathrm{C}$ for eighteen hours. The growth around the filter paper discs was thereafter observed. The sugars used were glucose, lactose, sucrose, galactose, raffinose and maltose. Growth around the paper discs indicated the ability of the isolate to assimilate a sugar.

\subsubsection{Chlamydospore Formation Test}

Each yeast isolate was inoculated on corn meal agar containing tween 80 and incubated at $25^{\circ} \mathrm{C}$ for seventy-two hours and thereafter introduced on a slide and stained with lactophenol cotton blue solution. The stained preparation was thereafter viewed under the microscope for chlamydospore formation.

\subsection{Screening Test for Aviation Fuel Utilization by the Microbial Isolates}

The mineral salts medium of Mills et al [16] was used. It was prepared and dispensed in $9.9 \mathrm{ml}$ amounts into test tubes. $0.1 \mathrm{ml}$ of the aviation fuel was introduced into each of the tubes which were thereafter sterilized by autoclaving and allowed to cool. Upon cooling, the tubes were inoculated with the microbial isolates individually and incubated at $28^{\circ} \mathrm{C}$ for fourteen days. The tubes were observed for turbidity and clarity which are indications of bacterial and fungal utilization respectively of the aviation fuel.

\subsubsection{Determination of the ${ }_{\mathrm{P}} \mathrm{H}$ of the Medium}

The ${ }_{\mathrm{P}} \mathrm{H}$ of the growth medium was taken before and at the end of the screening test using a ${ }_{\mathrm{p}} \mathrm{H}$ meter that was standardized with ${ }_{\mathrm{P}} \mathrm{H}$ buffers 4.0 and 7.0. The electrode was inserted into the test tubes and the values read and recorded.

\section{Results}

The microbial isolates from the aviation fuel are shown in Table 1. They were Micrococcus luteus, Serratia marcescens, Pseudomonas aeruginosa, Bacillus subtilis, Citrobacter freundii, Klebsiella aerogenes, Acinetobacter calcoaceticus, Fusarium oxysporum, Penicillium italicum, Rhizopus stolonifer, Aspergillus fumigatus and Candida tropicalis.

Table 1. Microbial Isolates from the Aviation Fuel.

\begin{tabular}{cc}
\hline Bacteria & Fungi \\
\hline Micrococcus luteus & Fusarium oxysporum \\
Serratia marcescens & Penicillium italicum \\
Pseudomonas aeruginosa & Rhizopus stolonifer \\
Bacillus subtilis & Aspergillus fumigatus \\
Citrobacter freundii & Candida tropicalis \\
Klebsiella aerogenes & \\
Acinetobacter calcoaceticus & \\
\hline
\end{tabular}

The distribution of the microbial isolates in the aviation fuel is shown in Table 2. Serratia marcescens were most frequently isolated (16\%) while Fusarium oxysporum and Candida tropicalis had the least distribution ( $4 \%$ each).

Table 2. Distribution of the Microbial Isolates in the Aviation Fuel.

\begin{tabular}{ccc}
\hline Microbial Isolates & No. of Isolates & Distribution (\%) \\
\hline Micrococcus luteus & 3 & 6 \\
Serratia marcescens & 8 & 16 \\
Pseudomonas aeruginosa & 6 & 12 \\
Bacillus subtilis & 4 & 8 \\
Citrobacter freundii & 3 & 6 \\
Klebsiella aerogenes & 3 & 6 \\
Acinetobacter & 5 & 10 \\
calcoaceticus & 2 & 4 \\
Fusarium oxysporum & 3 & 6 \\
Penicillium italicum & 6 & 12 \\
Rhizopus stolonifer & 5 & 10 \\
Aspergillus fumigatus & 2 & 4 \\
Candida tropicalis & 50 & 100 \\
TOTAL &
\end{tabular}

The aviation fuel utilization potentials of the microbial isolates is presented in Table 3. Serratia marcescens, Pseudomonas aeruginosa, Acinetobacter calcoaceticus, Rhizopus stolonifer and Aspergillus fumigatus utilized the fuel most while Fusarium oxysporum and Candida tropicalis were the least utilizers of the fuel.

Table 3. Aviation Fuel Utilization Potentials of the Microbial Isolates

\begin{tabular}{cc}
\hline Microorganisms & $\begin{array}{c}\text { Aviation fuel utilization } \\
\text { potentials }\end{array}$ \\
\hline Micrococcus luteus & ++ \\
Serratia marcescens & ++ \\
Pseudomonas aeruginosa & ++ \\
Bacillus subtilis & ++ \\
Citrobacter freundii & ++ \\
Klebsiella aerogenes & ++ \\
Acinetobacter calcoaceticus & +++ \\
Fusarium oxysporum & + \\
Penicillium italicum & ++ \\
Rhizopus stolonifer & +++ \\
Aspergillus fumigatus & +++ \\
Candida tropicalis & + \\
\hline
\end{tabular}

$+=$ Minimal growth, $++=$ Moderate growth, $+++=$ Heavy growth .

The ${ }_{\mathrm{p}} \mathrm{H}$ of the mineral salts-oil medium upon microbial 
inoculation and at fourteen days of inoculation are presented in Table 4. The ${ }_{\mathrm{p}} \mathrm{H}$ of the medium upon inoculation of the isolates singly was 7.4. A decrease in the ${ }_{\mathrm{P}} \mathrm{H}$ of the medium after fourteen days of microbial inoculation was more in the medium containing Serratia marcescens $\left({ }_{\mathrm{p}} \mathrm{H}\right.$ 5.2) while that containing Candida tropicalis had the least reduction $\left({ }_{\mathrm{p}} \mathrm{H} 6.6\right)$ in the ${ }_{\mathrm{P}} \mathrm{H}$ at fourteen days of microbial inoculation.

Table 4. ${ }_{\mathrm{pH}} \mathrm{H}$ of the Mineral Salts-Oil Medium upon Microbial Inoculation and at Fourteen Days of Inoculation

\begin{tabular}{ccc}
\hline Microbial Isolates & $\begin{array}{c}\mathrm{pH} \text { upon } \\
\text { Inoculation }\end{array}$ & $\begin{array}{c}{ }_{\mathrm{pH}} \text { at fourteen days of } \\
\text { inoculation }\end{array}$ \\
\hline Micrococcus luteus & 7.4 & 6.2 \\
Serratia marcescens & 7.4 & 5.2 \\
Pseudomonas & 7.4 & 5.3 \\
aeruginosa & 7.4 & 5.6 \\
Bacillus subtilis & 7.4 & 6.4 \\
Citrobacter freundii & 7.4 & 6.6 \\
Klebsiella aerogenes & 7.4 & 5.4 \\
Acinetobacter & 7.4 & 6.4 \\
calcoaceticus & 7.4 & 6.2 \\
Fusarium oxysporum & 7.4 & 5.9 \\
Penicillium italicum & 7.4 & 6.0 \\
Rhizopus stolonifer & 7.4 & 6.6 \\
Aspergillus fumigatus & & \\
Candida tropicalis & &
\end{tabular}

\section{Discussion}

Twelve microbial species were isolated from the commercial aviation fuel examined. They were Micrococcus luteus, Serratia marcescens, Pseudomonas aeruginosa, Bacillus subtilis, Citrobacter freundii, Klebsiella aerogenes, Acinetobacter calcoaceticus, Fusarium oxysporum, Penicillium italicum, Rhizopus stolonifer, Aspergillus fumigatus and Candida tropicalis (Table 1). This result is in agreement with the report of Denaro et al [17] and Rauch et al [2] who isolated Acinetobacter spp, Bacillus spp, Micrococcus spp, Serratia spp, Pseudomonas spp, Aspergillus spp, Fusarium spp, Penicillium spp and Candida spp from their aviation fuel samples.

More bacteria were isolated from the aviation fuel than the fungi. The percentage distribution of Serratia marcescens in the aviation fuel was highest $(16 \%)$ while Micrococcus luteus, Citrobacter freundii and Klebsiella aerogenes each had the least percentage distribution of $6 \%$ among the bacterial isolates. The fungus Rhizopus stolonifer had the highest percentage distribution of $12 \%$ in the aviation fuel while Fusarium oxysporum and Candida tropicalis each had the lowest percentage distribution of $4 \%$ in the fuel (Table 2).

The potentials of the bacterial and fungal isolates to utilize the aviation fuel as source of carbon and energy for growth was determined by observing the varying degree of turbidity and clarity for bacteria and fungi respectively, they produced while growing in the minerals salts-oil medium. Serratia marcescens, Pseudomonas aeruginosa, Acinetobacter calcoaceticus, Rhizopus stolonifer and Aspergillus fumigatus produced heavy turbidity in the medium indicating that they utilized the fuel more than the other isolates (Table 3). The better utilization of the aviation fuel by these isolates may be because of their massive growth and enzymes production which may be an indication that the cultural conditions were favourable to their growth.

There was also a reduction in the initial ${ }_{\mathrm{P}} \mathrm{H}$ of the mineral salts-oil medium. The highest reduction was in the medium inoculated with Serratia marcescens for the bacterial isolates $\left({ }_{\mathrm{p}} \mathrm{H}\right.$ 5.2) and in the medium inoculated with Rhizopus stolonifer for the fungal isolates $\left({ }_{\mathrm{p}} \mathrm{H}\right.$ 5.9) (Table 4). Microbial degradation of hydrocarbons often results in the production of acidic metabolites. The production of these metabolites probably resulted in the reduction in ${ }_{\mathrm{p}} \mathrm{H}$ observed in this study. These organisms isolated from the commercial aviation fuel studied have been reported as hydrocarbon degraders $[12,18,19]$.

The result of this study indicated that the aviation fuel samples examined were contaminated with bacteria and fungi, therefore vigorous inspection and maintenance of the aircraft fuel systems as well as the incorporation of safe biocides in the fuel are recommended. In addition, frequent drainage of water from the fuel tanks as well as regular microbiological examination of the fuel and its tanks must be prioritized.

\section{Conclusions}

Bacteria and fungi were isolated from the commercial aviation fuel examined. These organisms can cause problems in the fuel and to its users. The problem can be alleviated if water is constantly drained from the storage tanks and by the incorporation of effective biocides in the fuel. Frequent inspection of the fuel storage tanks is also recommended.

\section{REFERENCES}

[1] T. Edwards. Liquid Fuels and Propellants for Aerospace Propulsion: 1903/2003. Journal of Propulsion and Power. Vol. 19, No. 6, 1089-1107, 2003. DOI: 10.2514/2.6946.

[2] M.E. Rauch, H.W. Graef, S.M. Rozenzhak, S.E. Jones, C.A. Bleckmann, R.L. Kruger, R.R. Naik, M.O. Stone. Characterization of Microbial Contamination in United States Air Force Aviation Fuel Tanks. Journal of Industrial Microbiology and Biotechnology. Vol. 33, No.1, 29-36, 2006. DOI: 10.1007/s10295-005-0023-x.

[3] L.Q. Maurice, H. Lander, T. Edwards, W.E. Harrison. Advanced aviation fuels: a look ahead via a historical perspective. Fuel. Vol. 80, No. 5, 747-756 (10), 2001. DOI: http://dx.doi.org/10.1016/s0016-2361 (00)00142-3.

[4] S.T. Swift. Identification and control of microbial growth in 
fuel handling systems. In: M.M. Doris (Ed.) Distillate fuel contamination, storage and handling, Philadelphia. American Society for testing and materials. Pp 15-26, 1988.

[5] D.A. Vaccari, P.F. Strom, J.E. Alleman. Environmental Biology for Engineers and Scientists. Hoboken, N.J: John Wiley and Sons, Inc. PP 29-30, 2006.

[6] C.C. Gaylarde, F.M. Bento, J. Kelly. Microbial contamination of stored hydrocarbon fuels and its control. Revista de microbiologia. Vol. 30, No. 1, 1-10, 1999. http://dx.doi.org/10.1590/S0001-37141999000100001.

[7] P.K. S.M. Rahman, E. Gakpe. Production, Characterization and Applications of Biosurfactants-Review. Biotechnology. Vol. 7, No.2, 360-370, 2008. DOI: 10.3923/biotech.2008.360.370.

[8] J.D. Van Hamme, A. Singh, O.P. Ward. Recent advances in petroleum microbiology. Microbiology and Molecular Biology Reviews. Vol. 67, No.4, 503-549, 2003. doi:10.1128/MMBR.67.4.503-549.2003.

[9] K. Zhang, H. Choi, D.D. Dionysiru, G.A. Sorial, D.B. Oerther. Identifying pioneer bacterial species responsible for biofouling membrane bioreactors. Environmental Microbiology. Vol. 8, No.3, 433-400, 2006.

DOI:10.111/j.1462-2920.2005.00909.x.

[10] M.E. Davey, G.A. O’toole. Microbial biofilms: from Ecology to Molecular Genetics. Microbiology and Molecular Biology Reviews. Vol. 64, No.4, 847-867,2000. Doi:10.1128/MMBR.64.4.847-867.2000.

[11] J.W. Costerton, Z. Lewandowski, D.E. Caldwell, D.R. Korber, H.M. Lappin-Scott. Microbial Biofilms. Annual Review of Microbiology. Vol. 49, 711-745, 1995. http://www.ncbi.nlm. nih.gov/pubmed/8561477.

[12] S.C. Onuorah, M.N. Ikegbunam, S.N. Awah, J.O. Ezeadila. Microbial Contamination of Stored Diesel Oil in Nigeria. World Journal of Pharmacy and Pharmaceutical Sciences.
Vol. 2, No.3, 1459-1464, 2013.

http://www.wjpps.com/download/article/1375179.

[13] J.G. Holt. Bergey's Manual of determinative bacteriology. $9^{\text {th }}$ edition, Williams and Wilkins Company, Baltimore, USA. pp 72-720,1994

[14] S. Onuorah, T. Obika, U. Okafor. Filamentous Fungi Associated with the spoilage of post-harvest Sweet Orange Fruits (citrus sinensis) sold in Awka Major Markets, Nigeria. Bioengineering and Bioscience, vol. 3, No.3, 44-49,2015. DOI:10.13189/bb.2015.030303.

[15] N. Menza, W. Wanyoike, W.M. Muturi. Prevalence of vaginal candidiasis and determination of the occurrence of Candida species in pregnant women attending the ante-natal clinic of Thika district hospital, Kenya. Open Journal of Medical Microbiology, Vol. 3, No.4, 1-9, 2013. DOI:10.4236/ojmm.2013.34040.

[16] A.L. Mills, C. Breuil, R.R. Colwell. Enumeration of petroleum degrading marine and estuarine microorganisms by the most probable number method. Canadian Journal of Microbiology. Vol. 24, No.5, 552-557,1978. DOI: 10.1139/m78-089.

[17] T.R. Denaro, S.K. Chelgren, J.N. Lang, E. M. Strobel, L.M.T. Balster, M.D. Vangsness. DNA isolation of microbial contaminants in Aviation Turbine fuel via Traditional Polymerase Chain Reaction (PCR) and Direct PCR. Preliminary Results. Airforce Research Laboratory, Wright Patterson Airforce Base, Ohio 45433-7251. http://www.researchgate.net/publication/235126662.

[18] T. April, J.M. Foght, R.S. Currah. Hydrocarbon-degrading filamentous fungi isolated from flare pit soils in Northern and western Canada. Canadian Journal of microbiology. Vol. 46, No.1, 38-49, 2000. DOI:10.1139/w99-117.

[19] J. Oudot, J. Dupont, S. Haloui, M.F. Roquebert. Biodegradation potential of Hydrocarbon-Assimilating Tropical Fungi. Soil Biology and Biochemistry. Vol. 25, No.9, 1167-1173, 1993. DOI:10.1016/0038-0717 (93) 90211-S. 